\title{
PEMBERDAYAAN MASYARAKAT DESA PUJO RAHAYU KECAMATAN NEGERI KATON DI BIDANG SOSIAL, EKONOMI DAN KESEHATAN
}

\author{
Eka Ubaya Taruna Rauf ${ }^{1}$, Lies Kumara Dewi ${ }^{2}$, Apri Budi Hartono ${ }^{3}$ \\ Universitas Sang Bumi Ruwa Jurai \\ Program Studi Ilmu Administrasi Negara, Fakultas Ilmu Sosial Dan Ilmu Politik \\ Email: ekaubaya77@gmail.com
}

\begin{abstract}
Abstrak
Pelaksanaan pembangunan dan perkembangan teknologi informasi memerlukan kesiapan masyarakat desa Pujo Rahayu untuk mengantisipasi dampak yang ditimbulkan di berbagai bidang. Program ini bertujuan untuk melakukan pemberdayaan masyarakat yang melibatkan partisipasi aktif secara luas di semua bagian masyarakat di tingkat lokal di bidang ekonomi, kesehatan dan sosial. Program dilakukan melalui survey kondisi bangunan rumah tinggal warga, ceramah klasikal tentang teknologi informasi dan penggunaan gadget yang baik dan benar, diskusi- pelatihan tentang perpustakaan dan pembuatan hiasan kaligrafi, dan pelayanan kesehatan secara gratis. Dari program ini dihasilkan data fasilitas bangunan fisik warga dalam bentuk peta desa. Peningkatan kesadaran ibu-ibu tentang kemandirian ekonomi. Pemahaman masyarakat tentang cara pengaksesan dan pemanfaatan sumber informasi digital dan non-digital meningkat. Selain itu juga terjadi peningkatan partisipasi masyrakat dalam menjaga kesehatanya sendiri
\end{abstract}

Kata kunci: pemberdayaan, sosial, ekonomi

\begin{abstract}
The implementation of development and development of information technology requires the readiness of the Pujo Rahayu village community to anticipate the impacts in various fields. This program aims to carry out community empowerment that involves broad active participation in all sections of society at the local level in the economic, health and social fields. The program is carried out through surveys of the condition of residents' houses, classical lectures on information technology and proper and correct use of gadgets, discussions on libraries and making calligraphy ornaments, and free health services. From this program, data on residents' physical building facilities are generated in the form of village maps. Increased awareness of mothers about economic independence. People's understanding of how to access and utilize digital and non-digital information sources is increasing. In addition, there has also been an increase in community participation in maintaining their own health
\end{abstract}

Keywords: empowerment, social, economy

\section{PENDAHULUAN}

Pemerintah desa Pujo Rahayu menjadi unit terdepan pelayanan kepada masyarakat serta merupakan faktor utama untuk keberhasilan program. Memperkuat desa adalah suatu upaya untuk mempercepat terwujudnya individu dan masyarakat yang mandiri. Salah satu upayanya dengan melakukan pemberdayaan masyarakat khususnya bagi mereka yang kurang memiliki akses ke sumber daya pembangunan. Masyarakat didorong untuk meningkatkan kemandirian dalam mengembangkan peri kehidupan mereka, merupakan proses siklus terus-menerus, proses partisipatif yaitu anggota masyarakat bekerja sama dalam kelompok formal maupun informal, berbagi pengetahuan dan pengalaman serta berusaha mencapai tujuan bersama (Madekhan, 2007). Bentuk partipasi menjadi suatu elemen pokok dalam strategi pemberdayaan dan pembangunan masyarakat, karena partisipasi masyarakat merupakan perangkat ampuh dalam memobilisasi sumber daya lokal, dan dalam membantu pengidentifikasian secara dini terhadap kebutuhan masyarakat (Ali, 2007). Dengan terbitnya UU No 6 tahun 2014 tentang Desa mendorong desa sebagai subyek pembangunan yang berazaskan kebersamaan, 
kegotongroyongan, musyawarah, kekeluargaan, kemandirian, partisipasi, kesetaraan, pemberdayaan dan keberlanjutan. Informasi tersebut telah disampaikan secara masif baik dalam bentuk media cetak dan media digital. Namun, kemampuan masyarakat di desa untuk dapat memperoleh dan mengakses ataupun memilah dan memilih informasi baik media cetak maupun media digital tersebut masih sangat kurang.

Desa Pujo Rahayu merupakan salah satu dari 19 desa di wilayah Kecamatan Negeri katon Kabupaten Pesawaran yang dibuka/didirikan pada tahun 1919 dengan luas wilayah kurang lebih $475 \mathrm{Ha} / \mathrm{m}^{2}$ dengan jumlah penduduk sebanyak 898 Kepala Keluarga dan 3.660 Jiwa, yaitu 1.922 Laki-laki dan 1.738 Perempuan.

Semenjak berdiri pada tahun 1919 sampai saat ini desa Pujo Rahayu telah dipimpin oleh Beberapa Kepala Desa sebagai berikut :

\begin{tabular}{lll}
\hline No & Nama Kepala Desa & Masa Jabatan \\
$\mathbf{1}$ & Usup & Tahun 1921-1923 \\
$\mathbf{2}$ & M. Putus & Tahun 1923-1926 \\
$\mathbf{3}$ & Karto Diwiriyo & Tahun 1926-1948 \\
$\mathbf{4}$ & Cokro Soedono & Tahun 1948-1957 \\
$\mathbf{5}$ & Reso Diharjo & Tahun 1957-1965 \\
$\mathbf{6}$ & M. Haan & Tahun 1965-1968 \\
$\mathbf{7}$ & Mustolah & Tahun 1968-1980 \\
$\mathbf{8}$ & Hadi Suratno & Tahun 1980-1998 \\
$\mathbf{9}$ & Edi Sutarto & Tahun 1998-2006 \\
$\mathbf{1 0}$ & Teguh Junaidi & Tahun 2006-2012 \\
$\mathbf{1 1}$ & Apri Budi Hartono. SE & Tahun 2012- Sekarang \\
\hline
\end{tabular}

Sejalan dengan makna dan hakekat pembangunan, dengan mempertimbangkan kondisi masyarakat dan potensi sumber daya serta kekuatan yang dimiliki desa Pujo Rahayu, menetapkan visi dan Misi sesuai dengan tugas Pokok dan Fungsi Kepala Desa.

Visi Desa pujo Rahayu Kecamatan Negeri Katon adalah:

"Kebersamaan dalam membangun Demi Desa Pujo Rahayu yang lebih maju"

Misi Desa Pujo Rahayu Kecamatan Negeri Katon adalah:

1. Pembangunan Infrastruktur.

2. Pemberdayaan Sumber daya Manusia (SDM).

3. Peningkatan Sektor Pendidikan, Kesehatan dan keagamaan.

4. Optimalisasi bidang pertanian, Perkebunan dan Perikanan.

Berdasarkan permasalahan di atas maka perlu dilakukan program pemberdayaan masyarakat yang bertujuan untuk (a) menyajikan data dusun dalam bentuk peta yang informatif dan akurat, (b) meningkatkan pemahaman tentang penggunaan sumber informasi secara tepat, (c) memperluas pemahaman tentang kegiatan ekonomi kreatif yang dapat meningkatkan pendapatan, (d) meningkatkan pelayanan kesehatan kepada masyarkat terutama para lansia.

\section{METODE}

Program pemberdayaan ini dilakukan di Desa Pujo Rahayu melalui beberapa kegiatan, yaitu (a) penyusunan peta dusun yang melibatkan seluruh warga dalam pengisian data, (b) pendampingan kepada anak-anak, remaja dan orang tua tentang penggunaan alat komunikasi dan cara mengakses infromasi yang benar, (c) ceramah dan diskusi kepada para ibu-ibu tentang marketing dan ekonomi kreatif dari narasumber serta pelatihan kaligrafi kepada para pemuda dan (d) pelayanan kesehatan kepada masyarakat terutama para lansia. Penyusunan peta dusun 
dilakukan melalui pendataan, tabulasi dan menggambar peta desa. Pendataan dilakukan dengan cara membuat blangko isian yang diisi sewaktu mendatangi rumah tiap warga dan melakukan wawancara singkat tentang kondisi rumah dan fasilitas yang tersedia. Data tersebut dipresentasikan dalam bentuk peta dusun menggunakan software grafis dalam bentuk softfile dan dicetak pada kertas dan poster. Peta dusun tersebut dilengkapi dengan petunjuk informasi yang terkini di lapangan. Pemahaman tentang teknologi informasi disampaikan dalam kegiatan sosialisasi berupa ceramah klasikal dari sumber yang kompeten tentang cara mengakses informasi di dunia digital beserta dampak positif dan negatif gadget dan meda sosial. Sementara pengaksesan media cetak dilakukan dengan penyiapan taman bacaan atau perpustakaan dusun. Upaya untuk menunjang kegiatan ekonomi masyarakat dilakukan melalui sosialisasi marketing ibu-ibu PKK, dilakukan dengan cara mengumpulkan ibu-ibu PKK dan memberikan materi tentang marketing serta potensi ekonomi lokal melalui ceramah-klasikal dan praktik pembuatan kaligrafi dari narasumber kepada pemuda. Pelayanan kesehatan diberikan kepada warga terutama lansia melalui pengecekan kesehatan dan pemberian obatobatan ringan yang dilaksanakan di Balai Desa oleh bidan desa.

\section{Pendataan dan Pemetaan}

\section{HASIL DAN PEMBAHASAN}

Program pemetaan ini dilaksanakan karena melihat masih belum terbaruinya dan tercatatnya data dusun yang sesuai dengan keadaan yang ada di dusun sekarang, dimana pencatatan meliputi data keluarga, dan bangunan fisik tempat tinggal. Bangunan Fisik adalah tempat berlindung tetap maupun sementara, yang mempunyai dinding, lantai dan atap, baik digunakan untuk tempat tinggal maupun bukan tempat tinggal. Program ini dilaksanakan dengan mengunjungi rumah-rumah warga terutama di dusun 01 atau juga meminta KK di tiap rumah dan melakukan pencatatan untuk dimasukkan ke dalam blangko pendataan. Pemetaan menjadi penting karena dalam pemetaan ini akan ditampilkan tentang info-info denah rumah warga yang ada di dusun 01 beserta keterangan yang meliputi rumah dan info-info lainnya yang ada. Program ini dilaksanakan dengan cara melakukan survey ke lokasi masing-masing Dusun 01 desa Pujo Rahayu. Gambar wilayah Dusun 01 diperoleh dari citra satelit melalui peta Google Earth yang disesuaikan dengan kebutuhan. Dari hasil pendataan yang dilakukan, ditambahkan kolom keterangan. Pembuatan peta desa ini menggunakan software AutoCAD dan dicetak ke kertas A1 untuk disebar ke tiap-tiap rumah RW di dusun 01 (Gambar 1). Informasi berupa letak rumah dari nama kepala keluarga, kondisi rumah apakah layak huni atau tidak (dilihat dari kondisi dinding, lantai dan atap rumah), keberadaan fasilitas jamban dan terpasang atau tidaknya fasilitas listrik. Dengan hasil ini, pencarian lokasi dan pengidentifikasian kebutuhan masyarakat akan mudah dilakukan. Update data sebaiknya terus dilakukan setiap tahun.

Gambar 1 :

Balai Desa Pujo Rahayu Versi Lama, Peta Desa Pujo Rahayu dan Petunjuk Arah ke lokasi yang akan dituju
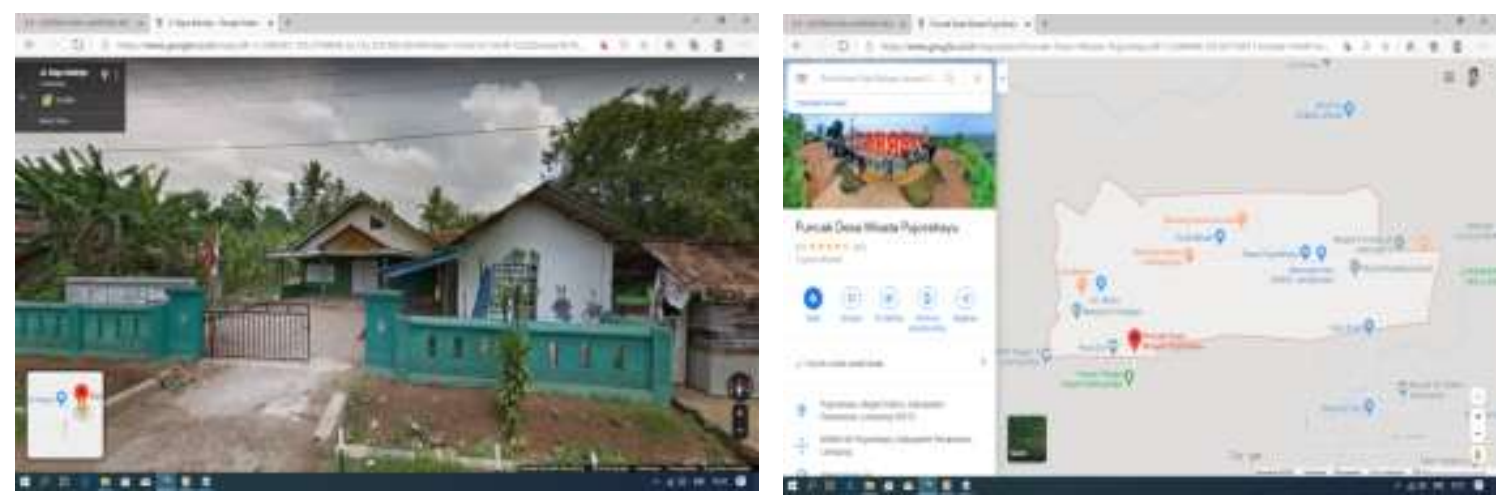


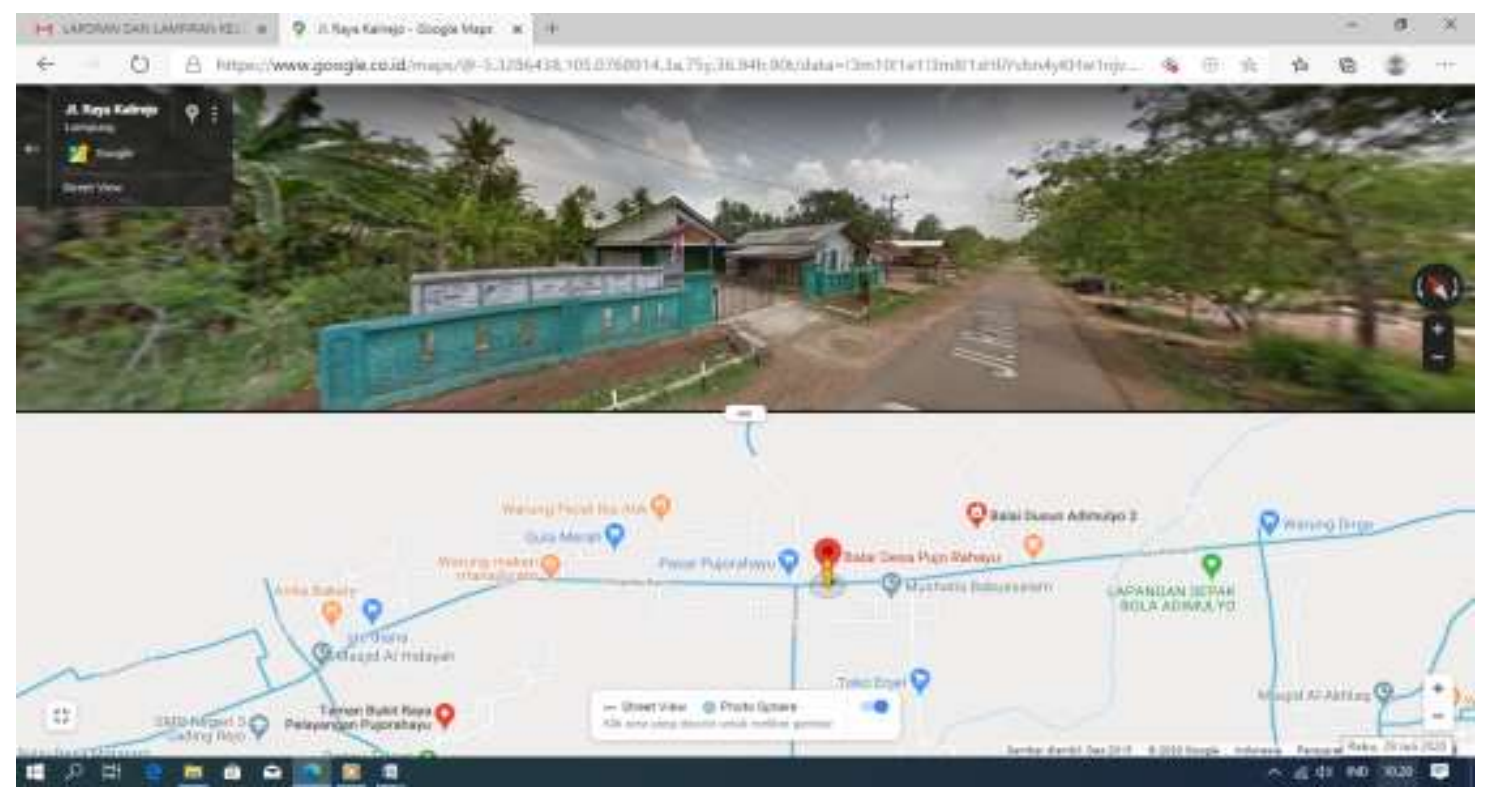

\section{Penyuluhan dan Pendampingan Sumber Informasi yang Sehat}

Program ini dilaksanakan karena masyarakat dan anak-anak sebagian besar sudah memiliki gadget baik itu berupa handphone atau dalam bentuk lain dan masih belum dapat memilah dan memilih konten-konten yang ada di dunia digital. Konten-konten di dunia digital tidak semua memuat hal yang bermanfaat namun ada juga yang bersifat mudharat. Selama penyuluhan disampaikan juga bagaimana mengakses situs-situs informasi resmi yang dapat dipertanggungjawabkan dan mengontrol akses untuk anak- anak (Gambar 2). Kegiatan ini dilaksanakan di Balai Desa Pujo Rahayu dengan narasumber yang kompeten di bidang teknologi informasi. Peserta sebagian terdiri dari bapak- bapak yang sudah berkeluarga sedangkan anak-anak dan remaja usia sekolah dasar sampai sekolah menengah atas Pada akhir program masyarakat dan anak-anak sudah mulai memahami konten-konten apa saja yang baik dan masyarakat lebih bijak dalam menggunakan media sosial serta gadget.

Gambar 2 :

Memilih konten-konten yang ada di dunia digital. Konten-konten di dunia digital tidak semua memuat hal yang bermanfaat namun ada juga yang bersifat mudharat
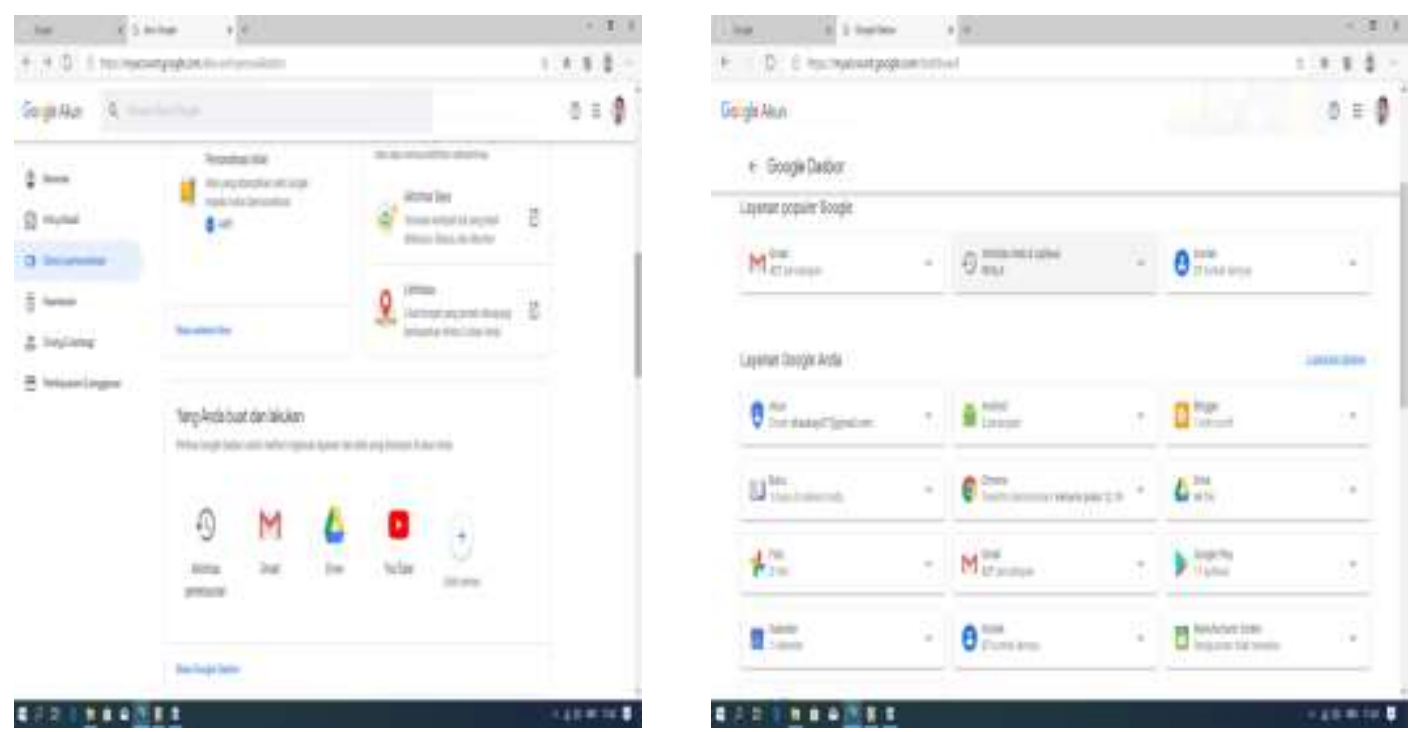
Selain itu, dalam penyuluhan juga disampaikan bagaimana mengakses informasi tentang buku dan surat kabar. Belum adanya tempat sebagai referensi baca bagi masyarakat khususnya dusun 01 adalah hal yang mendasari untuk melaksanakan program ini. Faktor penghambatnya mungkin lebih kepada penghimpunan buku dan media cetak yang sulit. Namun dengan melakukan metode donasi pribadi bahan media cetak lebih mudah terkumpul. Untuk itu dibuatlah taman bacaan yang memuat media cetak yang juga dapat digunakan untuk tempat bertukar fikiran dan berdiksusi warga masyarakat

\section{Penyuluhan dan Pendampingan Usaha Ekonomi Kreatif Ibu-Ibu PKK}

Ibu-ibu PKK desa Pujo Rahayu yang sebagian besar hanya berada di rumah untuk bekerja mengurus rumah tangga menjadi sasaran dalam program ini, karena mereka juga berkeinginan membantu perekonomian keluarga. Ibu-ibu masih takut dan belum memiliki niat untuk membuka usahanya sendiri karena masalah-masalah tertentu apalagi sekarang mas COVID-19 masih menajdi trending topik dimana mana bahkan sekarang sudah menurunkan saudaranya yaitu OTG. Program ini bersifat sosialisasi berbentuk seminar dengan membantu dan memberi ilmu kepada ibu- ibu di desa Pujo Rahayu untuk dapat berani membuka usahanya sendiri dan mengelola dengan baik dan benar agar dapat memajukan usahanya. Sosialisasi dilakukan di balai desa Pujo Rahayu dengan mengundang ibu-ibu untuk hadir, dengan menghadirkan pemateri dari dosen Fakultas Ilmu Sosial dan Ilmu Politik Universitas Sang Bumi Ruwa Jurai Bandar Lampung yaitu Ibu Henni Kusumastuti juga pegiat usaha ekonomi kreatif Bapak Erwin Putubasai yang memberikan materi tentang tata cara kelola sebuah usaha agar sesuai dengan prinsip-prinsip wirausaha (Gambar 3). Ditambahkan juga materi tentang usaha-usaha wirausaha yang dapat dilakukan dari rumah seperti pembuatan tanaman hidroponik dengan pemasaran melalui online. Para pemuda juga dberikan pendampingan untuk pelatihan pembuatan kaligrafi yang bertempat di masjid. Selain untuk melatih kemampuan hiasan grafis, kaligrafi hasil dari pelatihan disumbangkan kepada masjid terdekat dari lokasi pelatihan.

Gambar 3 :

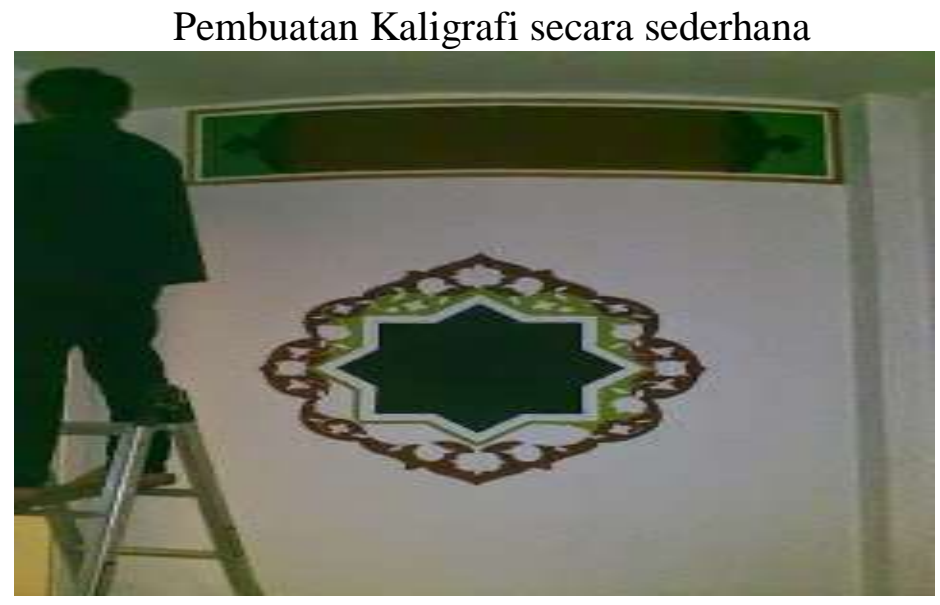

\section{Penyuluhan dan Pelayanan Kesehatan}

Fasilitas akses kesehatan yang masih terbatas di desa Pujo Rahayu, menyebabkan warga masyarakat dan para lansia yang semakin bertambah umur jarang memeriksakan keadaan kesehatan mereka. Disamping itu juga disebabkan keterbatasan fisik, waktu atau biaya. Padahal umur yang terus bertambah secara ilmiah juga akan menurunkan kapasitas daya imun seseorang sehingga sangat perlu adanya kesadaran dari diri sendiri untuk berusaha menjaga kesehatannya sendiri. Program ini dibantu tim kesehatan dari puskesmas bertempat di Balai Desa Pujo Rahayu. Acara dimulai dengan ceramah kesehatan untuk lansia dilanjutkan dengan cek kesehatan yang meliputi tekanan darah, cek darah rutin dan pemberian obat yang 
sesuai. Dalam pelaksanaannya juga diberikan konsultasi kesehatan secara individu kasus per kasus sesuai kondisi masing-masing peserta. Para lansia di desa Pujo Rahayu sangat antusias untuk memeriksakan kondisi kesehatannya, sehingga terjadi antrian yang cukup panjang dengan jumlah peserta mendekati seratus peserta, namun kegiatan ini dapat berjalan dengan tertib dan lancar. Kedepan diharapkan dapat terbentuk desa siaga untuk pemberdayaan masyarakat agar mau dan hidup sehat sehingga upaya kesehatan yang dilakukan lebih tercapai (accessible), lebih terjangkau (affordable), dan lebih berkualitas (quality) apalagi di masa Pandemi Mas COVID-19 dengan afiliasinya OTG.

\section{KESIMPULAN}

Dari hasil program pengabdian kepada masyarakat yang telah dilaksanakan dapat disimpulkan manfaat yang dapat diambil sebagai berikut:

1. Tersedianya peta Dusun yang menyediakan informasi terkini dan akurat tentang lokasi masing-masing kepala keluarga, kondisi kelayakan huni dari rumah warga, ketersediaan jamban dan listrik di masing-masing rumah warga sehingga memudahkan pemerintah desa untuk mengambil keputusan.

2. Warga masyarakat dan anak-anak dapat menjadi lebih mengerti tentang tata cara penggunaan gadget dan media sosial untuk hal yang bermanfaat dan dengan berdirinya taman bacaan di rumah Kepala Desa Pujo Rahayu, dapat menjadikannya sebagai tempat untuk menambah informasi dan diskusi antar warga.

3. Ibu-ibu mendapat wawasan untuk dapat memulai suatu usaha dan tata cara kelola agar usaha tersebut dapat maju yang pada akhirnya ibu-ibu PKK desa Pujo Rahayu menjadi lebih mandiri.

4. Kondisi kesehatan para lansia dapat dimonitor secara berkala.

\section{UCAPAN TERIMA KASIH}

Terima kasih disampaikan kepada Lembaga Penelitian dan Pengabdian Masyarakat Universitas Sang Bumi Ruwa Jurai dan Yayasan Pendidikan Saburai atas pendanaan program ini yang merupakan Pengabdian kepada Masyarakat 2020

\section{DAFTAR PUSTAKA}

Ali, M. dkk. ( 2007). Pemberdayaan Masyarakat. Paradigma Aksi Metodologi. Jakarta : PT Pelangi Nusantara.

Badan Pusat Statistik (BPS). (2018). Pemetaan 2018: Pedoman Pemetaan Desa Buku 3, Badan Pusat Statistik, Jakarta Departemen Kesehatan RI, " Keputusan Menkes RI Nomor 564/Menkes/SK/VIII/2006 tentang Pedoman Pelaksanaan Pengembangan Desa Siaga", Tanggal 2 Agustus 2006

Madekhan, A. (2007). Orang Desa Anak Tiri Perubahan. Jakarta Averroes Press

Sofianto, A. (2017). Kontribusi Dana Desa Terhadap Pembangunan dan Pemberdayaan Masyarakat

Undang-Undang Republik Indonesia Nomor 6 tahun 2014, Tentang Desa 